\title{
Highly sensitive detection of ALK resistance mutations in plasma using droplet digital PCR
}

Ryohei Yoshida ${ }^{*}$, Takaaki Sasaki ${ }^{1}$, Yasuhiro Umekage ${ }^{1}$, Sachie Tanno ${ }^{1}$, Yusuke Ono ${ }^{2}$, Munehiko Ogata ${ }^{2}$, Shinichi Chiba ${ }^{3}$, Yusuke Mizukami ${ }^{2,4}$ and Yoshinobu Ohsaki ${ }^{1}$

\begin{abstract}
Background: On-target resistance mechanisms found in one-third of patients receiving anaplastic lymphoma kinase (ALK) tyrosine kinase inhibitors (TKIs) are secondary ALK mutations in ALK-rearranged non-small cell lung cancer (NSCLC). There are large variations in the resistant mutations, unlike the epithelial growth factor receptor (EGFR) T790 M seen with the use of EGFR-TKls. Liquid biopsy approaches using cell-free DNA (cfDNA) are used for screening and monitoring of mutations in NSCLC. However, feasible protocol for the simultaneous detection of multiple secondary ALK mutations using droplet digital PCR (ddPCR) has not been developed. An efficient strategy using cfDNA in cancer diagnostics, the development of more accurate and cost-effective tools to identify informative multiple secondary ALK mutations is clinically required.
\end{abstract}

Methods: To establish a feasible assay to monitor ALK-TKI resistance mutations, we first evaluated the feasibility of ddPCR-based screening for cfDNA mutation detection of 10 distinct secondary ALK mutations. Positive samples were then re-analyzed using mutation-specific probes to track the growth of mutation clones with a high sensitivity.

Results: Blood samples from seven ALK-positive patients were analyzed using the ddPCR protocol. Secondary G1202R $A L K$ mutations were identified in 2 of 7 patients by the screening assay. Using the mutation-specific probes, monitoring the resistant clone during the clinical course of the disease was well demonstrated in each of the patients.

Conclusion: The protocol for ddPCR-based liquid biopsy has a feasibility for the screening of secondary ALK-TKI resistance mutations and offers a tool for a cost-effective monitoring of progression in NSCLC.

Keywords: Resistance, ALK inhibitors, Liquid biopsy, Cell-free DNA (cfDNA), Droplet digital PCR (ddPCR)

\section{Background}

In 2007, anaplastic lymphoma kinase $(A L K)$ was discovered as a potential target in non-small cell lung cancer (NSCLC) [1]. In a small subset of NSCLC tumors, a chromosomal inversion event leads to fusion of a portion of the $A L K$ gene with the echinoderm microtubuleassociated protein-like 4 (EML4) gene. The resulting EML4-ALK fusion protein is constitutively active and transforming, leading to a state of oncogene addiction. $A L K$ rearrangements included EML4-ALK fusions have

\footnotetext{
* Correspondence: yryohei@asahikawa-med.ac.jp

${ }^{1}$ Respiratory Center, Asahikawa Medical University, 2-1-1-1

Midorigaoka-Higashi, Asahikawa, Hokkaido 078-8510, Japan

Full list of author information is available at the end of the article
}

been identified in $3-7 \%$ of patients with NSCLC (herein referred to as "ALK-positive" lung cancer) [2].

In patients with $A L K$-positive NSCLC, the ALK inhibitor crizotinib resulted in significant higher rates of response with an objective response rate (ORR) of $74 \%$ and a median progression-free survival (PFS) of 10.9 months than chemotherapy [3]. Multiple mechanisms of crizotinib resistance have been described in $A L K$-positive NSCLC, with secondary mutations in the ALK kinase domain having been detected in approximately $20 \%$ of patients, most commonly L1196 M (the "gate-keeper" mutation) and G1269A [4-6].

Although next-generation ALK inhibitors such as alectinib, ceritinib, and brigatinib are now available for preclinical and clinical testing, little is known about the

(c) The Author(s). 2018 Open Access This article is distributed under the terms of the Creative Commons Attribution 4.0 International License (http://creativecommons.org/licenses/by/4.0/), which permits unrestricted use, distribution, and reproduction in any medium, provided you give appropriate credit to the original author(s) and the source, provide a link to the Creative Commons license, and indicate if changes were made. The Creative Commons Public Domain Dedication waiver (http://creativecommons.org/publicdomain/zero/1.0/) applies to the data made available in this article, unless otherwise stated. 
potential mechanisms of resistance to these agents. In one small study, some patients who relapsed on ceritinib were found to have acquired new tumor mutations in the ALK kinase domain, either at position G1202 or at position F1174 [7]. The fact that the more commonly occurring crizotinib-resistant $A L K$ mutations (i.e., L1196 M and G1269A) were not observed in ceritinibresistant samples, suggesting that different patterns of resistance will emerge depending on the selective pressure of the individual ALK inhibitors for deriving resistant tumor subclones.

Preclinical studies have demonstrated that alectinib is active against the crizotinib-resistant $A L K$ mutations L1196 M, C1156Y, and F1174 L, implying that alectinib may be effective in patients who have developed a resistant to crizotinib through other mechanisms [8, 9]. Gainor et al. reported the spectrum and frequency of the numerous known secondary mutations of ALK inhibitors in 103 patients with $A L K$-positive NSCLC [6], showing that a high frequency of G1202R mutation was a common feature of each ALK inhibitor. Recently, lorlatinib as a 3rd-generation ALK inhibitor has been developed and is expected to have a therapeutic effect on secondary mutations, including G1202R [10]. Although treatment strategies using multiple ALK inhibitors against secondary mutations is rapidly developing, the methods for detecting the actual causal genes in the clinic have not been established.

Tissue biopsy is a gold-standard for the molecular diagnosis of lung cancer; however, serial sampling is not feasible as a routine assessment for the recurrent tumor. Genomic (g) DNA shed from tumors into the general circulation has been intensively studied for monitoring tumor genetics and offers opportunities to trace the genomic evolution of cancer systematically $[11,12]$. Sometimes referred to as "liquid biopsy", genotyping of cell-free DNA (cfDNA) isolated from plasma and other body fluid represents an attractive non-invasive tool to monitor cancer progression and response to treatments (e.g. resistance). Given advances in sequencing technology, recent studies have demonstrated that the mutations detected by the cfDNA genotyping are highly concordant to those obtained by tumor biopsy [13, 14]. In addition, such an approach may overcome the problems associated with intratumor or intra-lesion genetic heterogeneity since the liquid biopsy using next-generation sequencing (NGS) will be able to cover the whole genetic landscape of tumor in all its complexity in near future [15].

An efficient strategy using cfDNA in cancer diagnostics, the development of more accurate and cost-effective tools to identify informative mutations is clinically required. The analysis of cfDNA using NGS is still expensive, time-consuming, and its value in clinical practice is limited. Among the new technologies for quantifying cfDNA, droplet digital PCR (ddPCR) provides the highest sensitivity for detecting and tracking actionable mutations at frequencies as low as $0.05-0.01 \%$ [1618]. In the current study, we sought to establish a liquid biopsy protocol for ddPCR-based detection of multiple TKI-induced secondary mutations in $A L K$-positive NSCLC patients. We also describe clinical course of patients with G1202R-positive NSCLC in details.

\section{Methods \\ Patients}

Seven patients with $A L K$-positive NSCLC, previously treated or undergoing treatment, were examined between January 2015 and December 2016 at the Asahikawa Medical University Hospital, Asahikawa, Japan. All patients were diagnosed with $A L K$-positive NSCLC by fluorescence in situ hybridization (FISH) or immunohistochemistry (IHC). Patients were treated with daily crizotinib or alectinib. The Standard Response Evaluation Criteria in Solid Tumors (RECIST 1.0) was used to evaluate treatment responses. We obtained written informed consents from all study participants, and the study was approved by the Institute of Biomedical Research and Innovation Research Ethics Committee.

\section{Sample collection and DNA extraction}

Blood collection was performed every 3 months during ALK inhibitor treatment as long as blood samples were scored as being positive in the first screening step. Blood samples (limited to $<16 \mathrm{~mL}$ ) were collected in $8 \mathrm{~mL}$ tubes containing EDTA-2 K (SPM-L1008EMS; Sekisui Medical, Co., Ltd.), with plasma isolated within $2 \mathrm{~h}$. Tubes were centrifuged at $1,100 \mathrm{~g}$ for $10 \mathrm{~min}$ at room temperature. After the first centrifugation, tubes were centrifuged at $18,000 \mathrm{~g}$ for $10 \mathrm{~min}$ at $4{ }^{\circ} \mathrm{C}$ (Fig. 1). The supernatant, containing cell-free plasma, was collected in $2 \mathrm{~mL}$ serum tubes and stored at $-80{ }^{\circ} \mathrm{C}$ until purification. For the purification process, cfDNA was isolated from cell-free plasma in a volume of $2-4 \mathrm{~mL}$ with the QIAamp Circulating Nucleic Acid kit (Qiagen, Hilden, Germany) according to the manufacture's protocol. Finally, cfDNA was extracted with elution buffer in volume of $100 \mu \mathrm{L}$. After purification, cfDNA aliquots were quantified with the Qubit dsDNA HS Assay Kit (Thermo Fisher Scientific, Waltham, MA, USA) and a Qubit 3.0 Fluorometer (Thermo Fisher Scientific).

\section{Detection of ALK resistance mutations in cfDNA}

To detect ALK inhibitor resistance mutations in cfDNA, we used a ddPCR genotyping assay in conjunction with the QX200 Droplet Digital PCR System (Bio-Rad, Hercules, USA). The cfDNA was analyzed in two steps. In the first (screening) step, cfDNA was analyzed with the multiplex 


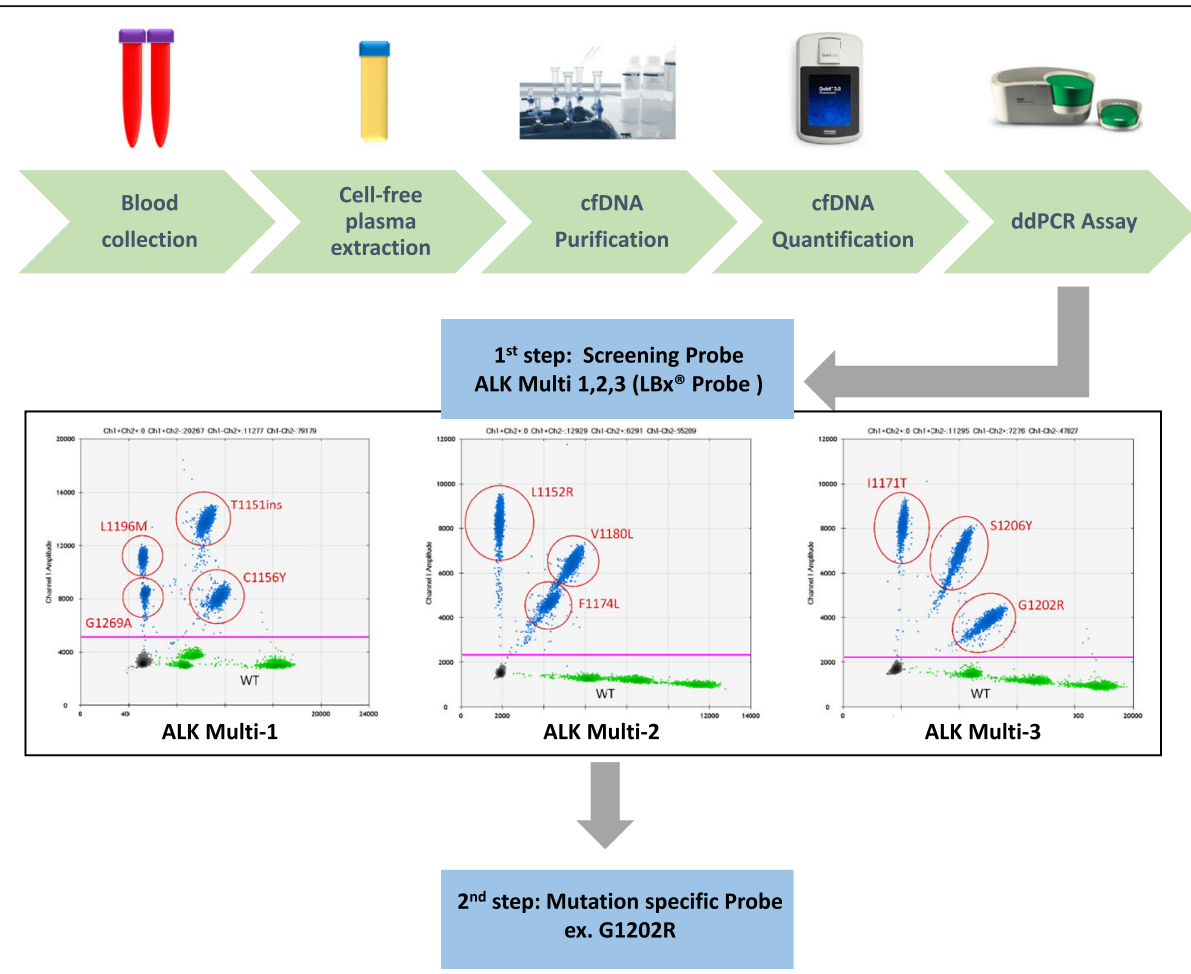

Fig. 1 Schematic outlining the protocol used to detect recurrent ALK mutations from plasma-derived cfDNA. Firstly, blood collection from patients with ALK-positive NSCLC was performed, cell-free plasma was extracted. The cfDNA was isolated in the purification process and quantified using Qubit. We used a ddPCR genotyping assay in conjunction with the QX200 Droplet Digital PCR System. The cfDNA was analyzed in two steps. In the first step, cfDNA was analyzed using screening probes. In the second step, cfDNA mutations detected in the screening phase were re-analyzed with mutation-specific probes

probes LBx ${ }^{\circ}$ Probes ALK Multi-1, -2, and - 3 (Riken genesis, Tokyo, Japan). The probe cocktails cover the ALK-TKI mutations T1151ins, C1156Y, L1196 M, G1269A (ALK Multi-1), L1152R, F1174 L, and V1180 L (ALK Multi-2), and I1171T, G1202R, and S1206Y (ALK Multi-3). The combination of these three probe sets thus allows for the detection of 10 recurrent $A L K$ mutations simultaneously. In the second step, cfDNA mutations detected in the screening phase were re-analyzed with mutation-specific probes (Integrated DNA Technologies), designed to increase probe binding specificity and thus track the progression of low mutation cfDNA fractions during the clinical course. All probes in the second step were diluted to be $100 \mu \mathrm{M}$ with indicated volume of TE Buffer.

\section{Droplet digital PCR system}

Reaction mixtures were prepared (Additional file 1: Table S1), and partitioned into $\sim 22,000$ droplets per sample by mixing with $70 \mu \mathrm{L}$ of Droplet Generation Oil (Bio-Rad) in a QX200 droplet generator (Bio-Rad). Droplets were then subjected to thermal cycling with a Veriti Thermal Cycler (Thermo Fisher Scientific) (Additional file 1: Table S2), before transferring to a QX200 droplet reader (Bio-Rad) for fluorescence measurement of 6-fluorescein amidite (FAM) and hexachloro-fluorescein (HEX) probes. Droplets were scored as positive or negative based on their fluorescence intensity, which was determined by gating thresholds, defined with positive and negative controls. Finally, absolute copy number input in the reaction and the ratio of mutated fragments was calculated by QuantaSoft ver 1.7 (Bio-Rad), based on a Poisson distribution. Samples were scored as positive for the mutation when at least two mutation droplets were detected using screening probes, or at least three mutation droplets were detected by mutation-specific ddPCR.

\section{Mutation-specific detection of ALK G1202R and I1171T}

Probes (Integrated DNA Technologies) used in the mutation-specific assay contained locked nucleic acid (LNA) bases, which increase probe binding specificity and enable the detection of low mutation cfDNA fractions [19]. ALK G1202R and I1171T probe and primer sequences were designed (Additional file 1: Table S3A).

\section{Sensitivity and specificity of the mutation-specific ddPCR assay}

To confirm the sensitivity and specificity of the specific mutations (G1202R and I1171T), we performed preliminary experiments using gBlocks ${ }^{\circ}$ gene fragments (Integrated DNA Technologies) for wild-type and mutant $A L K$ 
(Additional file 1: Table S3B). The $A L K$ G1202R fragment was mixed with $A L K$ wild-type DNA in ratios of 1:10 (10\%), 1:100 (1\%), 1:1,000 (0.1\%), 1:10,000 (0.01\%), and 1:100,000 (0.001\%), and amplified with probes for wild-type $A L K$ (HEX) which include both fused and non-fused of ALK and G1202R mutation (FAM) (Additional file 2: Figure S1). The limitation of detection for $A L K$ G1202R was found to be $0.01 \%$ mutation DNA. \% mut were calculated from generated Poisson concentrations as follows:

$$
\% \text { mut }=\frac{(F A M)}{(F A M+H E X)} \times 100 .
$$

\section{Next-generation sequencing}

Genomic DNA from brain metastasis biopsy tissue (case \#1) was isolated using the DNeasy Blood \& Tissue Kit (Qiagen) according to the manufacturer's protocol. Ion AmpliSeq Colon and Lung Cancer Research Panel v2 (Thermo Fisher Scientific), a previously validated panel for targeted amplicon sequencing was utilized (Thermo Fisher Scientific) [20]. Briefly, 10 nanograms of gDNA was amplified by PCR using Ion AmpliSeq Library Kit (Thermo Fisher Scientific) and the sequencing was performed on an Ion PGM System according to the manufacturer's protocol. Sequencing reads were multiplexed, quality-filtered, and aligned to the human reference genome (GRCh37) using the Torrent Suite software (ver. 5.0.4; Thermo Fisher Scientific). Variants were identified with the Variant Caller software (ver. 5.0.4.0; Thermo Fisher Scientific). The quality of all variants called was manually confirmed by IGV software (ver. 2.3.59).

\section{Results}

\section{cfDNA in ALK-positive patients}

Seven consecutive $A L K$-positive NSCLC patients were enrolled in this study. Six patients were already treated with the ALK-TKIs crizotinib or alectinib (Fig. 2 and Additional file 1: Table S4). Following cfDNA analysis in the first screening step,2 of 7 patients (28.6\%) were scored as being positive. Case 1 observed ALK G1202R mutation during alectinib treatment and Case 2 also observed ALK G1202R mutation during crizotinib treatment. In the 3 patients who received alectinib treatment after crizotinib failure, tumors were still controlled (2 cases of CR and, 1 case of PR), mutation screening were negative for all 10 secondary mutations. The rest of patient was still on going with crizotinib treatment, with only obtained pre-treatment sample which was scored as negative for secondary mutations with the screening probe cocktails. In Case \#1, we could successfully detect resistance mutation samples from serial blood collection during ALK-TKI treatment, also could validate the data from ddPCR and NGS analysis from tumor sample. The

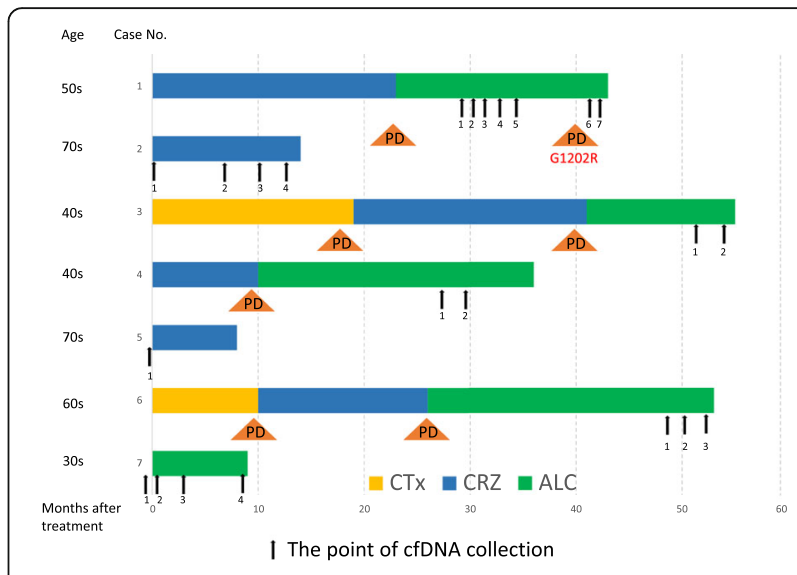

Fig. 2 Patients characteristics; cfDNA collection from patients and treatment schedule. The timing of cfDNA collection (black allow) and each bar shows treatment period (CTX, chemotherapy, yellow: $C R Z$ crizotinib, blue: ALC, alectinib, green). The number under the black arrow represents the timing of cfDNA collection in each case. cfDNA concentration and cfDNA input per well for each patient is shown in Additional file 1: Table S4. Triangle PD represents the timing of disease progression

clinical course of the case with the acquired resistance was described below in greater detail.

\section{Case \#1}

A Japanese in his fifties with a history of NSCLC, that had undergone right upper lobe resection and mediastinal lymph node dissection, was diagnosed with postoperative recurrence in lung harboring an $A L K$-rearrangement by FISH. After 23 months treatment with crizotinib, pericardial effusion and right pleural effusion were found (Fig. 3a $\&$ b). Following diagnosis of progressive disease on crizotinib, medication was changed to the alternative ALK-TKI alectinib. The patient initially maintained partial clinical response on alectinib therapy, but brain metastasis was developed 17 months later (Fig. 3c). gDNA extracted from the brain tumor biopsy was sequenced and G1202R ALK mutation was found (variant allele frequency 26.5\%; Additional file 2: Figure S2A). The recurrent ALK G1202R mutation in the patient matched at the nucleotide levels with the gBlock used as the $A L K$ G1202R positive control.

Serial blood samples taken at seven points following the alectinib therapy $(6,8,9,11,13,19$ and 20 months) were analyzed by the ddPCR screening protocol as described in the Materials and Methods. The G1202R mutation was identified with the ALK Multi-3 assay, being first detectable 11 months after the alectinib therapy (Additional file 2: Figure S2B). No $A L K$ mutations were detected using ALK Multi-1 or ALK Multi-2 probes.

Subsequently, these samples were re-analyzed using the mutation-specific assay. The G1202R mutation was detected 9 months after the therapy and the mutant fraction was increased over time (Fig. 3d). In contrast, 
A
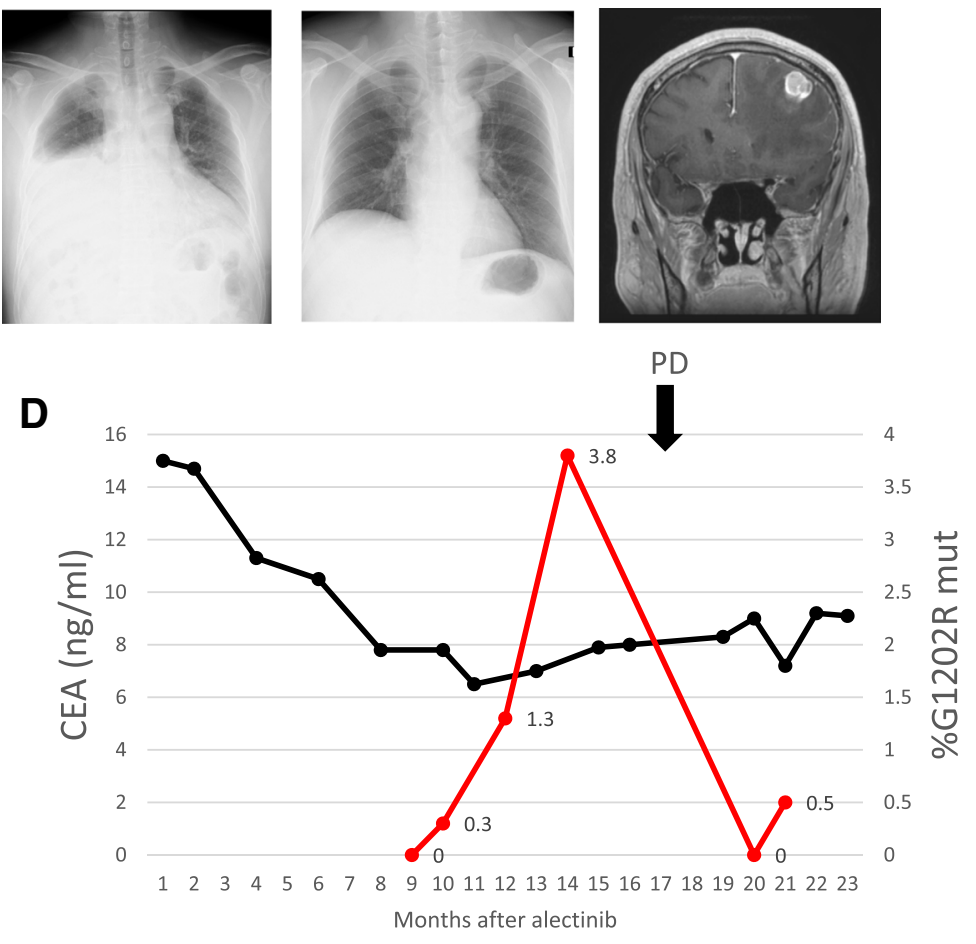

B

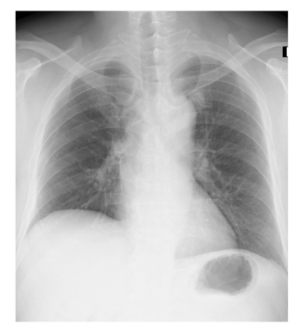

C

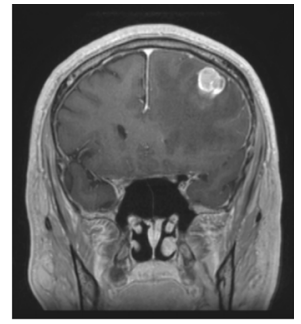

CEA: Carcinoembryonic antigen

Fig. 3 Case \#1. (a) Chest radiography showing PD 23 months after treatment with crizotinib, with pericardial effusion and right pleural effusion. (b) Chest radiography 13 months after treatment with alectinib. Imaging revealed a moderate response in pericardial effusion and right pleural effusion. (c) MRI imaging showing PD (brain metastasis) 17 months after treatment with alectinib. (d) Graph shows the change of \% G1202R mut in cfDNA using ddPCR and CEA levels during the clinical course after treatment with alectinib. \% G1202R mut $=\frac{(\text { FAM })}{(\text { FAM+HEX })} \times 100$.

$\mathrm{PD}=$ Progressive disease

CEA levels remained above the reference value $(5 \mathrm{ng} / \mathrm{ml})$ during the observation period and alectinib failure was not demonstrated. The time between the plasma cfDNAbased progressive disease and recurrence of the brain metastasis was 8 months. After resection of the brain metastasis, the frequency of G1202R mutation decreased. The patient was treated with alectinib as beyond PD therapy, but there were no progression on alectinib five months after resection of the brain metastasis (Fig. 3d \& Additional file 2: Figure S3C).

\section{Discussion}

In this study, we established a protocol for liquid biopsybased ddPCR detection of multiple secondary mutations in $A L K$-positive NSCLC patients. In the first screening step, we can identify multiple $A L K$ mutations with high sensitivity, while in the second mutation-specific step we are able to monitor disease progression and thus ALKTKI clinical efficacy. Using this protocol, we report two cases in which the $A L K$ mutation G1202R emerged as a mechanism of resistance to ALK-TKIs or G1202R mutation detected during treatment with crizotinib and it was not associated with resistance to this drug.

Recently, liquid biopsy using cfDNA for screening or monitoring of response to treatment has become more widely used, with studies reporting a concordance of 70$80 \%$ between tissue and plasma mutations identified in NSCLCs $[21,22]$. Although this figure indicates that there is still room for improvement, liquid biopsy approaches using cfDNA have the potential to address some important clinical problems. One is the issue of intra-tumor heterogeneity, wherein the population of mutated, resistant and wildtype clones may change over time under the selection pressure of targeted therapy [23]. Another problem is the challenge of performing multiple and potentially difficult biopsies, such as those involving bronchoscopy, for the purpose of monitoring disease progression. In this study, we have established an effective protocol for liquid biopsy-based ddPCR detection of multiple ALK-TKI resistance mutations in $A L K$-positive NSCLC patients. In this protocol, multiplex probes ALK Multi1, -2 , and -3 were initially used for screening, with mutation-specific 
probes (e.g., for G1202R) then used to monitor disease progression.

In contrast to ALK-TKI resistance, in which many secondary mutations have been reported [5, 24], half of the acquired resistance to epithelial growth factor receptor (EGFR) TKI therapy has been shown to be due acquisition of a single point mutation T790 M [24]. Consequently, many strategies have been developed to detect T790 M mutations with high sensitivity. The amplification-refractory mutation system (ARMS) is one such assay that has been developed to detect mutations using cfDNA in the blood. Wang et al. reported that, comparing ddPCR with ARMS in 75 patient plasma samples, the rates of T790 M mutation detection were $46.7 \%$ by ddPCR, and $25.3 \%$ by ARMS [25]. This result suggests that $\mathrm{ddPCR}$ assay may provide greater sensitivity than ARMS to detect the EGFR T790 M mutation in plasma. In the present study, we were similarly able to detect $A L K$ mutations in plasmaderived cfDNA using a highly sensitive ddPCR approach. Since it is known that multiple secondary mutations may be involved in the development of resistance to ALK-TKIs [5, 24], it is important to screen $A L K$-positive patients for a wide-range of potential mutations, as we have described here. The mutation-specific G1202R assay that we designed contained LNA, which is a high-affinity DNA analogue that hybridizes to cDNA and this chemistry contributes to an improvement in detection specificity [26]. Importantly, we were able to use this protocol to identify two NSCLC patients who developed G1202R point mutations as a mechanism of resistance to ALK-TKIs or G1202R mutation detected during treatment with crizotinib and it was not associated with resistance to this drug. In Case No. 1, especially, the plasma levels of the $A L K$ mutation corresponded with the patient's clinical course, indicating that this is an approach that has clinical utility for the monitoring of therapeutic effect. ALK G1202R has been shown to confer resistance to crizotinib and second-generation ALK inhibitors in both preclinical and clinical studies [4-6, 27]. This is the first case who treated with crizotinib harboring G1202R mutation. EML4-ALK protein thought to generate dimerization or trimerization which causes phosphorylation of ALK protein. The ALK TKI potency difference between ALK-WT/ALK-G1202R heterodimer or ALK-WT/ALK-G1202R/ALK-G1202R heterotrimer and ALK-G1202R homodimer or ALK-G1202R trimer may be one of the explanation $[28,29]$. There is a limitation of our study using this protocol. Our results showed that only limited number of patients and were analyzed in a single institutional experience. In order to further validation, we are planning multi-institutional study.

\section{Conclusions}

This is the first protocol described for the liquid biopsybased ddPCR detection of multiple ALK-TKI secondary resistance mutations in ALK-positive NSCLC patients. A limitation of this study is that the number of patient samples was small; however, the results indicate that there may be clinical benefit in monitoring the emergence of resistance mutations to provide early evidence of disease progression in NSCLC. A long-term surveillance study in a larger cohort of patients is now warranted to confirm these important findings.

\section{Additional files}

Additional file 1: Table S1. Reaction mixtures. (A) Screening assay. (B) Mutant specific assay. Table S2. Thermal cycling conditions. (A) Screening assay. (B) Mutant specific assay. Table S3. Mutation-specific detection. (A) ALK G1202R and 11171 T probe and primer. (B) gblocks ${ }^{\circledast}$ gene fragments. Table S4. cfDNA concentration and cfDNA input volume for patients. (DOCX $20 \mathrm{~kb}$ )

Additional file 2: Figure S1. Sensitivity and specificity of mutant specific assay for the ALK G1202R mutation. (A) Ch1 amplitude using G1202R mutation probe (FAM); (B) Ch2 amplitude using Wt probe (HEX); (C) Copy number of positive droplets for the G1202R mutation (Mt, blue bar) and wildtype (Wt, green bars), with the red numbers indicating $\%$ G1202R mut $=\frac{(\text { FAM })}{(\text { FAM }+ \text { HEX })} \times 100$. gblocks, Mutant G1202R (Mt) and wildtype (Wt) DNA was mixed at ratios of 1:10 (10\%), 1:100 (1\%), 1:1000 (0.1\%), 1:10000 (0.01\%), and 1:100000 (0.001\%), while mutant I1171T and wildtype DNA was mixed at a ratio of 1:100 (1\%) (rightmost bar). Figure S2. (A) Next-generation sequencing analysis of the brain metastasis sample of Case 1. Brain metastasis biopsy tissue was analyzed using nextgeneration sequencing. The picture was taken with the Integrative Genomics Viewer. In this picture, targeted NGS identified an acquired $C \rightarrow T$ mutation in $26.5 \%$ of reads, encoding for an ALK G1202R mutation (COSM144250). (B) Two dimensions graph shows plot of the ddPCR count of plasma ALK mutation using ALK Multi3 probe in the first screening step. The patient plasma sample surrounded by the red circle was taken 11 months after alectinib treatment. The groups surrounded by black circles show each positive control (mutation 11171T, blue; G1202R, orange). Ch1 amplitude using G1202R mutation probe (FAM); Ch2 amplitude using Wt probe (HEX). (C) Ch1 amplitude using G1202R mutation probe (FAM); Ch2 amplitude using Wt probe (HEX); Copy number of positive droplets for the G1202R mutation (Mt, blue bar) and wildtype (Wt, green bars), with the red numbers indicating $\%$ G1202R mut $=\frac{(\text { FAM })}{(\text { FAM+HEX })} \times 100$. ddPCR count of plasma ALK G1202R mutation and correlation with clinical course. Patient samples were taken at seven points after administration of alectinib $(6,8,9,11,13,19$ and 20 month). Figure S3. (A) Two dimensions graph shows plot of the ddPCR count of plasma ALK mutation using ALK Multi3 probe in the first screening step. The patient plasma sample surrounded by the red circle was taken at 1 month after crizotinib treatment. The groups surrounded by black circles show each positive control (mutation I1171T, blue; G1202R, orange). (B) Ch1 amplitude using G1202R mutation probe (FAM); Ch2 amplitude using Wt probe (HEX); Copy number of positive droplets for the G1202R mutation (Mt, blue bar) and wildtype (Wt, green bars), with the red numbers indicating $\%$ G1202R mut $=\frac{(\text { FAM })}{(\text { FAM HEX })} \times 100$. Correlation of the ddPCR count of plasma ALK G1202R mutation with clinical course. Patient samples were taken at four points after administration of alectinib; 1, 7, 11, 13 months. (PPTX $4319 \mathrm{~kb}$ )

\section{Abbreviations}

ALK: anaplastic lymphoma kinase; ARMS: amplification-refractory mutation system; CEA: Carcinoembryonic antigen; cfDNA: cell-free DNA; ddPCR: droplet digital PCR; EGFR: epithelial growth factor receptor; EML4: echinoderm microtubule-associated protein-like 4; FAM: fluorescence measurement of 6fluorescein amidite; FISH: fluorescence in situ hybridization; HEX: hexachloro- 
fluorescein; IHC: immunohistochemistry; LNA: locked nucleic acid; NGS: nextgeneration sequencing; NSCLC: non-small cell lung cancer; ORR: objective response rate; PFS: progression-free survival; TKIs: tyrosine kinase inhibitors

\section{Acknowledgements}

The authors are thankful to Riken genesis for providing ALK Multi 1,2,3 (LBx Probe) ddPCR scatter figure (Fig. 1).

\section{Funding}

This study was supported by a Grant-in-Aid for Young Scientists B (Grant Number 26860595 to T.S.), JSPS KAKENHI Grant Number 15 K09239 (to S.T.) and by Grant-in-Aid for Regional R\&D Proposal-Based Program from Northern Advancement Center for Science \& Technology of Hokkaido, Japan (to Y.O. and Y.M.)

\section{Availability of data and materials}

The datasets used and/or the analyzed current report are available from the corresponding author upon reasonable request.

\section{Authors' contributions}

RY participated in drafting, and revising the manuscript. TS participated in preparing and conducting this research. YU and ST performed in the analysis and acquisition of data of the lung cancer. YO1 (Yusuke Ono), MO, SC and MY analyzed and interpreted the patient data. YO2 (Yoshinobu Ohsaki) participated in drafting and revising all versions of the manuscript. All authors read and approved the final manuscript.

\section{Ethics approval and consent to participate}

The study protocol was approved by the ethics committee of the Asahikawa Medical University. All participants provided consent to participate in the study and written informed consent was obtained from the patient for publication of this report and any accompanying tables and images.

\section{Consent for publication}

Not applicable.

\section{Competing interests}

The author declare that they have no competing interests.

\section{Publisher's Note}

Springer Nature remains neutral with regard to jurisdictional claims in published maps and institutional affiliations.

\section{Author details \\ ${ }^{1}$ Respiratory Center, Asahikawa Medical University, 2-1-1-1 Midorigaoka-Higashi, Asahikawa, Hokkaido 078-8510, Japan. ${ }^{2}$ Institute of Biomedical Research, Sapporo Higashi Tokushukai Hospital, Hokkaido, Japan. ${ }^{3}$ Center for Advanced Research and Education, Asahikawa Medical University, Hokkaido, Japan. ${ }^{4}$ Division of Gastroenterology and Hematology/Oncology, Department of Medicine, Asahikawa Medical University, Hokkaido, Japan.}

Received: 8 January 2018 Accepted: 1 November 2018

\section{Published online: 19 November 2018}

\section{References}

1. Soda M, Choi YL, Enomoto M, Takada S, Yamashita Y, Ishikawa S, Fujiwara S, Watanabe $\mathrm{H}$, Kurashina $\mathrm{K}$, Hatanaka $\mathrm{H}$, et al. Identification of the transforming EML4-ALK fusion gene in non-small-cell lung cancer. Nature. 2007:448(7153):561-6.

2. Koivunen JP, Mermel C, Zejnullahu K, Murphy C, Lifshits E, Holmes AJ, Choi HG, Kim J, Chiang D, Thomas R, et al. EML4-ALK fusion gene and efficacy of an ALK kinase inhibitor in lung cancer. Clin Cancer Res. 2008;14(13):4275-83.

3. Solomon BJ, Mok T, Kim DW, Wu YL, Nakagawa K, Mekhail T, Felip E, Cappuzzo F, Paolini J, Usari T, et al. First-line crizotinib versus chemotherapy in ALK-positive lung cancer. N Engl J Med. 2014;371(23):2167-77.

4. Katayama R, Shaw AT, Khan TM, Mino-Kenudson M, Solomon BJ, Halmos B, Jessop NA, Wain JC, Yeo AT, Benes $C$, et al. Mechanisms of acquired crizotinib resistance in ALK-rearranged lung cancers. Sci Transl Med. 2012;4(120):120ra117.

5. Gainor JF, Dardaei L, Yoda S, Friboulet L, Leshchiner I, Katayama R, DagogoJack I, Gadgeel S, Schultz K, Singh M, et al. Molecular mechanisms of resistance to first- and second-generation ALK inhibitors in ALK-rearranged lung Cancer. Cancer Discov. 2016;6(10):1118-33.
6. Gainor JF, Varghese AM, Ou SH, Kabraji S, Awad MM, Katayama R, Pawlak A, Mino-Kenudson M, Yeap BY, Riely GJ, et al. ALK rearrangements are mutually exclusive with mutations in EGFR or KRAS: an analysis of 1,683 patients with non-small cell lung cancer. Clinical cancer research : an official journal of the American Association for Cancer Research. 2013;19(15):4273-81.

7. Friboulet L, Li N, Katayama R, Lee CC, Gainor JF, Crystal AS, Michellys PY, Awad MM, Yanagitani N, Kim S, et al. The ALK inhibitor ceritinib overcomes crizotinib resistance in non-small cell lung cancer. Cancer Discov. 2014;4(6):662-73.

8. Sakamoto H, Tsukaguchi T, Hiroshima S, Kodama T, Kobayashi T, Fukami TA, Oikawa N, Tsukuda T, Ishii N, Aoki Y. CH5424802, a selective ALK inhibitor capable of blocking the resistant gatekeeper mutant. Cancer Cell. 2011; 19(5):679-90.

9. Kodama T, Tsukaguchi T, Yoshida M, Kondoh O, Sakamoto H. Selective ALK inhibitor alectinib with potent antitumor activity in models of crizotinib resistance. Cancer Lett. 2014;351(2):215-21.

10. Zou HY, Friboulet L, Kodack DP, Engstrom LD, Li Q, West M, Tang RW, Wang H, Tsaparikos K, Wang J, et al. PF-06463922, an ALK/ROS1 inhibitor, overcomes resistance to first and second generation ALK inhibitors in preclinical models. Cancer Cell. 2015;28(1):70-81.

11. Schwarzenbach $H$, Hoon DS, Pantel K. Cell-free nucleic acids as biomarkers in cancer patients. Nat Rev Cancer. 2011;11(6):426-37.

12. Wan JC, Massie C, Garcia-Corbacho J, Mouliere F, Brenton JD, Caldas C, Pacey S, Baird R, Rosenfeld N. Liquid biopsies come of age: towards implementation of circulating tumour DNA. Nat Rev Cancer. 2017;17(4):223-38.

13. Mok TS, Wu YL, Ahn MJ, Garassino MC, Kim HR, Ramalingam SS, Shepherd FA, He Y, Akamatsu $H$, Theelen WS, et al. Osimertinib or platinumPemetrexed in EGFR T790M-positive lung Cancer. N Engl J Med. 2017;376(7): 629-40.

14. Sorber L, Zwaenepoel K, Deschoolmeester V, Van Schil PE, Van Meerbeeck J, Lardon F, Rolfo C, Pauwels P. Circulating cell-free nucleic acids and platelets as a liquid biopsy in the provision of personalized therapy for lung cancer patients. Lung cancer (Amsterdam, Netherlands). 2017;107:100-7.

15. De Mattos-Arruda L, Weigelt B, Cortes J, Won HH, Ng CK, Nuciforo P, Bidard FC, Aura C, Saura C, Peg V et al: Capturing intra-tumor genetic heterogeneity by de novo mutation profiling of circulating cell-free tumor DNA: a proof-of-principle. Annals of oncology : official journal of the European Society for Medical Oncology 2014, 25(9):1729-1735.

16. Oxnard GR, Paweletz CP, Kuang Y, Mach SL, O'Connell A, Messineo MM, Luke JJ, Butaney M, Kirschmeier P, Jackman DM, et al. Noninvasive detection of response and resistance in EGFR-mutant lung cancer using quantitative next-generation genotyping of cell-free plasma DNA. Clinical cancer research : an official journal of the American Association for Cancer Research. 2014:20(6):1698-705.

17. Pinheiro LB, Coleman VA, Hindson CM, Herrmann J, Hindson BJ, Bhat S, Emslie KR. Evaluation of a droplet digital polymerase chain reaction format for DNA copy number quantification. Anal Chem. 2012;84(2):1003-11.

18. Taly V, Pekin D, Benhaim L, Kotsopoulos SK, Le Corre D, Li X, Atochin I, Link $D R$, Griffiths AD, Pallier K, et al. Multiplex picodroplet digital PCR to detect KRAS mutations in circulating DNA from the plasma of colorectal cancer patients. Clin Chem. 2013;59(12):1722-31.

19. Johnson MP, Haupt LM, Griffiths LR. Locked nucleic acid (LNA) single nucleotide polymorphism (SNP) genotype analysis and validation using realtime PCR. Nucleic Acids Res. 2004;32(6):e55.

20. Tsongalis GJ, Peterson JD, de Abreu FB, Tunkey CD, Gallagher TL, Strausbaugh LD, Wells WA, Amos Cl. Routine use of the ion torrent AmpliSeq Cancer hotspot panel for identification of clinically actionable somatic mutations. Clin Chem Lab Med. 2014;52(5):707-14.

21. Sundaresan TK, Sequist LV, Heymach JV, Riely GJ, Janne PA, Koch WH, Sullivan JP, Fox DB, Maher R, Muzikansky A, et al. Detection of T790M, the acquired resistance EGFR mutation, by tumor biopsy versus noninvasive blood-based analyses. Clinical cancer research : an official journal of the American Association for Cancer Research. 2016;22(5):1103-10.

22. Xu S, Lou F, Wu Y, Sun DQ, Zhang JB, Chen W, Ye H, Liu JH, Wei S, Zhao $M Y$, et al. Circulating tumor DNA identified by targeted sequencing in advanced-stage non-small cell lung cancer patients. Cancer Lett. 2016; 370(2):324-31.

23. Piotrowska Z, Niederst MJ, Karlovich CA, Wakelee HA, Neal JW, MinoKenudson M, Fulton L, Hata AN, Lockerman EL, Kalsy A, et al. Heterogeneity underlies the emergence of EGFRT790 wild-type clones following treatment of T790M-positive cancers with a third-generation EGFR inhibitor. Cancer discovery. 2015;5(7):713-22. 
24. Yu HA, Arcila ME, Rekhtman N, Sima CS, Zakowski MF, Pao W, Kris MG, Miller VA, Ladanyi M, Riely GJ. Analysis of tumor specimens at the time of acquired resistance to EGFR-TKI therapy in 155 patients with EGFR-mutant lung cancers. Clinical cancer research : an official journal of the American Association for Cancer Research. 2013;19(8):2240-7.

25. Wang W, Song Z, Zhang Y. A comparison of ddPCR and ARMS for detecting EGFR T790M status in ctDNA from advanced NSCLC patients with acquired EGFR-TKI resistance. Cancer medicine. 2017;6(1):154-62.

26. Ray A, Norden B. Peptide nucleic acid (PNA): its medical and biotechnical applications and promise for the future. FASEB journal : official publication of the Federation of American Societies for Experimental Biology. 2000; 14(9):1041-60.

27. Kwak EL, Bang YJ, Camidge DR, Shaw AT, Solomon B, Maki RG, Ou SH, Dezube BJ, Janne PA, Costa DB, et al. Anaplastic lymphoma kinase inhibition in non-small-cell lung cancer. N Engl J Med. 2010;363(18):1693-703.

28. Richards MW, Law EW, Rennalls LP, Busacca S, O'Regan L, Fry AM, Fennell DA, Bayliss R: Crystal structure of EML1 reveals the basis for Hsp90 dependence of oncogenic EML4-ALK by disruption of an atypical betapropeller domain. Proc Natl Acad Sci of the United States of America 2014, 111(14):5195-5200

29. Richards MW, O'Regan L, Roth D, Montgomery JM, Straube A, Fry AM, Bayliss R. Microtubule association of EML proteins and the EML4-ALK variant 3 oncoprotein require an $\mathrm{N}$-terminal trimerization domain. The Biochemical journal. 2015;467(3):529-36.

Ready to submit your research? Choose BMC and benefit from:

- fast, convenient online submission

- thorough peer review by experienced researchers in your field

- rapid publication on acceptance

- support for research data, including large and complex data types

- gold Open Access which fosters wider collaboration and increased citations

- maximum visibility for your research: over $100 \mathrm{M}$ website views per year

At $\mathrm{BMC}$, research is always in progress.

Learn more biomedcentral.com/submissions 